\title{
Interactive comment on "Comparison of total water vapour content in the Arctic derived from GPS, AIRS, MODIS and SCIAMACHY" by Dunya Alraddawi et al.
}

\author{
Dunya Alraddawi et al. \\ dunia.alraddawi@latmos.ipsl.fr \\ Received and published: 2 November 2017
}

The authors would like to thank the anonymous referee for his/her valuable perspectives and suggestions, we are pleased to answer all the questions.

Question 1: Can it be explained what AIRS clear-sky forward mode absolute accuracy $0.2 \mathrm{~K}$ means for TCWV derivation (for MODIS given 5-10\% TCWV accuracy, page 4, line 35)?

AC Answer 1: The sentence giving the accuracy of AIRS radiances in temperature (Page 6 L21) was replaced with a statement on accuracy of water vapour retrievals:

Printer-friendly version

Discussion paper 
"The RMSE of the AIRS water vapor profiles is estimated to $10-15 \%$ over $2-\mathrm{km}$ layers in the troposphere (Fetzer et al., 2003; Divakarla et al., 2006)."

Question 2: Section 4 describes an impact of clouds on satellite TCWV measurements as a source of uncertainties. Is it the only or main factor creating the biases or does there exist other factors like latitudinal dependence? Is it possible to quantify all the disturbing factors?

AC Answer 2: In this publication, we focus on the clouds effect on satellites measurements despite the use of cloud cleared TCWV products, as one of the main factors affecting the satellites biases, but not the only one. Our answer is resumed in three points:

a. The global validation efforts of the three satellites products are cited in the manuscript. They show the other factors affecting the biases. However, the following text could be added at Page 3 L14 in the introduction:

"The global validation efforts of the used satellites products discussed many factors affecting the satellites biases. For example, both MODIS (Gao and Kaufman, 2003) and AIRS (Fetzer et al., 2006) TCWV retrievals are limited by the accurate initialization of the humidity profile. While SCIAMACHY measurements are independents of initial humidity profile, but affected by other factors like the albedo estimation for different surfaces (Noël, 2007). MODIS measurements are known to be affected by hazy conditions, and to be less accurate over dark surfaces (albedo effect as SCIAMACHY). Generally, satellites measurements are more accurate during clear sky conditions. However cloud clearing is a challenging task. The present publication uses cloud cleared products in order to assess their uncertainties for three Arctic stations. Moreover, it suggests a possible relation between these three satellites biases and the cloud cover making use of an available cloud fraction product to facilitate the study."

b. Results reveal that the inter-annual variability agreement (of MODIS and GPS, or SCIAMACHY and GPS) is getting better with latitude for the Arctic studied stations.

Interactive

comment

Printer-friendly version

Discussion paper 
However, the limited extent of the studied area $\left(67^{\circ} \mathrm{N}-78^{\circ} \mathrm{N}\right)$ doesn't really allow discussing the variation of biases with latitude.

c. Overall, we do believe that biases at lower latitude studied site (Sodankyla) are more affected by the surface type of the studied site than by clouds. However, the biases sensitivity to clouds occurrence has more obvious latitudinal feature. This is thought to be linked to the type of clouds dominant within the atmospheric column over both higher latitude studied sites, which is mentioned in the manuscript and suggested to be investigated.

Question 3: Figures 7, 8, 9 - is there any idea why Sodankyla is excluded from these figures, however discussed in sections $4.1,4.2$ and 4.3 ?

AC Answer 3: Figures 7, 8, and 9 illustrate the correlations only at the two higher latitude stations (Ny-Alesund and Thule) where the impact of clouds is the strongest. The discussion of Sodankyla in Section 4.1, 4.2, and 4.3 is based on the results reported in Table. 3. The lower correlations at Sodankyla are also due to other factors than clouds (vegetated surface and the snow composition in winter as mentioned in the manuscript).

Question 4: What can be concluded about the total uncertainties of the space-born instruments and deriving TCWV (instrumental uncertainties, models...), the outlook for calibrating satellite measurements with GNSS TCWV?

AC Answer 4: We think that the cloud clearing processes is still challenging for MODIS and SCIAMACHY. Additionally, TCWV conversion model of both MODIS and SCIA$\mathrm{MACHY}$ need to be improved to enable more realistic estimation of surface albedo regardless the complexity of the surface (vegetated snow covered surfaces). We can complete the end of the conclusion with:

". . and then improve space-borne instrumental uncertainties. This publication recommends the use of GNSS/TCWV in the calibration of similar satellite measurements."

Interactive

comment

Printer-friendly version

Discussion paper 
1.GPS or GNSS, if it cannot be claimed that the authors have used solely GPS-data (i.e. without GLONASS) what is very unlikely for repro2 solution, then the authors should better use GNSS instead of GPS in the title and the following text.

AC comment: Accepted, GPS will be replaced by GNSS.

Interactive comment

2. Page 4, lines 19-20 as "inter-annual variability (Fig. 2)", and Figure 2: Monthly time series. It could be more informative to give inter-annual variability as a table. It is hard to notice/quantify the variability from 10+ year TCWV time series (too much squeezed). Or, it could be pointed on Figures 7, 8 and 9?

AC comment: In this sentence we wanted to highlight that the year to year variations of TCWV at the three stations are smaller than the seasonal cycle (Fig.1). This can mainly be seen for summer values (i.e. the peak values) but not as much for the other seasons. The goal was not to be quantitative in this statement. However, we think that some readers might be interested in additional quantitative assessments. We therefore provide our monthly TCWV data in a supplement. The sentence P4 L19-20 is changed to:

"Figure 2 shows that the year to year variations of TCWV at the three stations are smaller than the seasonal cycle (Fig.1). This can be easily seen for summer values (peak values)."

\section{List of references:}

Divakarla, M. G., Barnet, C. D., Goldberg, M. D., McMillin, L. M., Maddy, E., Wolf, W., Zhou, L. and Liu, X.: Validation of Atmospheric Infrared Sounder temperature and water vapor retrievals with matched radiosonde measurements and forecasts, J. Geophys. Res. Atmos., 111(9), 1-20, doi:10.1029/2005JD006116, 2006.

Fetzer, E., Mcmillin, L. M., Tobin, D., Aumann, H. H., Gunson, M. R., Mcmillan, W. W., Hagan, D. E., Hofstadter, M. D., Yoe, J., Whiteman, D. N., Barnes, J. E., Bennartz, R.,

Printer-friendly version

Discussion paper 
Vömel, H., Walden, V., Newchurch, M., Minnett, P. J., Atlas, R., Schmidlin, F., Olsen, E. T., Goldberg, M. D., Zhou, S., Ding, H., Smith, W. L. and Revercomb, H.: AIRS / AMSU / HSB Validation, , 41(2), 418-431, 2003.

Fetzer, E. J., Lambrigtsen, B. H., Eldering, A., Aumann, H. H. and Chahine, M. T.: Biases in total precipitable water vapor climatologies from Atmospheric Infrared Sounder and Advanced Microwave Scanning Radiometer, J. Geophys. Res. Atmos., 111(9), 2006.

Gao, B.-C. and Kaufman, Y. J.: Water vapor retrievals using Moderate Resolution Imaging Spectroradiometer (MODIS) near-infrared channels, J. Geophys. Res. Atmos., 108(D13), n/a-n/a, doi:10.1029/2002JD003023, 2003.

Noël, S.: Product Specification Document for SCIAMACHY water vapour column swath data derived using the AMC-DOAS method., 2007.

Interactive comment on Atmos. Meas. Tech. Discuss., doi:10.5194/amt-2017-195, 2017. 